presence of orbital cellulitis, draining fistula, abscess, compressive effects on important orbital structures, persisting inflammation, or communication between orbit and intracranial cavity or paranasal sinuses. ${ }^{12}$

When a patient presents with a clinical picture suggesting an intraorbital foreign body but without a wound, the nose should be considered as a possible route of entry.

1 Holt GR, Holt JE. Management of orbital trauma and foreign bodies. Otolaryngol Clin North Am 1988;21: 35-52.

2 Espaillat A, Enzer Y, Lipsky S. Intraorbital metallic foreign body. Arch Ophthalmol 1998;116:824-5.

\title{
Just a pulled hamstring?
}

\author{
A P Mattick, T F Beattie, M F Macnicol
} Children's NHS Trust, Edinburgh A P Mattick T F Beattie M F Macnicol

Correspondence to: Mr A Mattick, Accident and Emergency Department, Royal Infirmary of Edinburgh, 1 Lauriston Place, Edinburgh EH3 9YW.
The diagnosis of an avulsion of the ischial apophysis in the adolescent is often missed or delayed due to the patient being considered to have sustained a muscular rupture or tendon tear of the hamstring group. ${ }^{1}$ The signs and symptoms of the conditions are similar. However, if there is bony tenderness and swelling at the origin of the hamstrings or a palpable gap in this region, then an avulsion is likely. The avulsion results from the powerful contraction of the hamstring muscles and often occurs during sporting activities. ${ }^{2}$ Between puberty and up to 25 years of age, the ischial apophysis is the weakest link in the chain of muscle, tendon, epiphysis, and bone. Thus it is the most vulnerable site when stressed. ${ }^{3}$ After this age the apophysis fuses with the innominate bone rendering an avulsion a rarity. To illustrate the above we present the following case in a young sportsman.

A 15 year old boy was participating in a sprint relay when he suddenly pulled up due to a sudden pain in his right buttock. He was originally diagnosed as having sustained a strained hamstring muscle and treated conservatively with rest and physiotherapy. Three months later, after no improvement, a plain radiograph showed an avulsion of the right ischial apophysis (fig 1). He was again treated conservatively. At six months after the injury he was referred for an orthopaedic opinion, via our accident and emergency department, because of the difficulty in resuming his pre-injury sporting activities. At this stage operative management was seriously considered but a conservative approach continued after discussion with both patient and his parents. At 10 months after the injury he was asymptomatic despite lack of bony union radiologically.

Recognition of this condition is important



Figure 1 Avulsion of the right ischial apophysis.

avulsion is recommended if it is displaced more than $2 \mathrm{~cm}$. In such cases operative reduction and internal fixation will lead to fewer symptoms such as discomfort on sitting, subjective and objective muscle weakness, as well as a return to sporting ability. To aid early diagnosis, we advocate radiological investigation in those patients with suspected hamstring injuries with bony tenderness at the origin of the hamstrings or a palpable gap in this vicinity. If an avulsion of the ischial apophysis is found then orthopaedic referral should be made for possible operative fixation. stretching should not be advised for four weeks. Rehabilitation can begin at the time of diagnosis to maintain the general physical fitness of the athlete without stressing the injury. Secondly, surgical fixation of the
1 Kujala UM, Orava S. Ischial apophysis injuries in athletes. Sports Med 1993;16:290-4

2 Wotten JR, Cross MJ, Holt KW. Avulsion of the ischial apophysis. The case for open reduction and internal fixation. $\mathcal{F}$ Bone foint Surg Br 1990;72:625-7. 
3 Brandser EA, el-Khoury GY, Kathol MH, et al. Hamstring injuries: radiographic, conventional tomographic, CT, an MR imaging characteristics. Radiology 1995;197:257-62.
4 Kujala UM, Orava S, Jarvinen M. Hamstring injuries. Current trends in treatment and prevention. Sports Med 1997 23:397-404.

\title{
Eye muscle paralysis after Vipera aspis envenomation
}

\author{
G Re, G Trisolino, F Miglio
}

A 22 year old man was bitten on his left foot by a snake identified as Vipera aspis. He was admitted to our emergency department 40 minutes later. On arrival, the patient was confused (Glasgow coma scale 14), pale, and tachycardic ( 120 beats $/ \mathrm{min})$. His respiration rate was $40 / \mathrm{min}$ and blood pressure $95 / 50 \mathrm{~mm}$ $\mathrm{Hg}$; temperature was $36.1^{\circ} \mathrm{C}$. Peripheral perfusion was good. The left foot was oedematous. Neurological examination revealed facial diplegia, bilateral ptosis, external ophthalmoplegia (fig 1). A slight abnormality of pupillary accommodation was observed. The first cranial nerve was not involved and dysphonia was not observed. Limb and trunk strength was normal. Tendon, plantar, and abdominal reflexes were regular. Muscle enzymes were within the normal range (serum creatine phos-

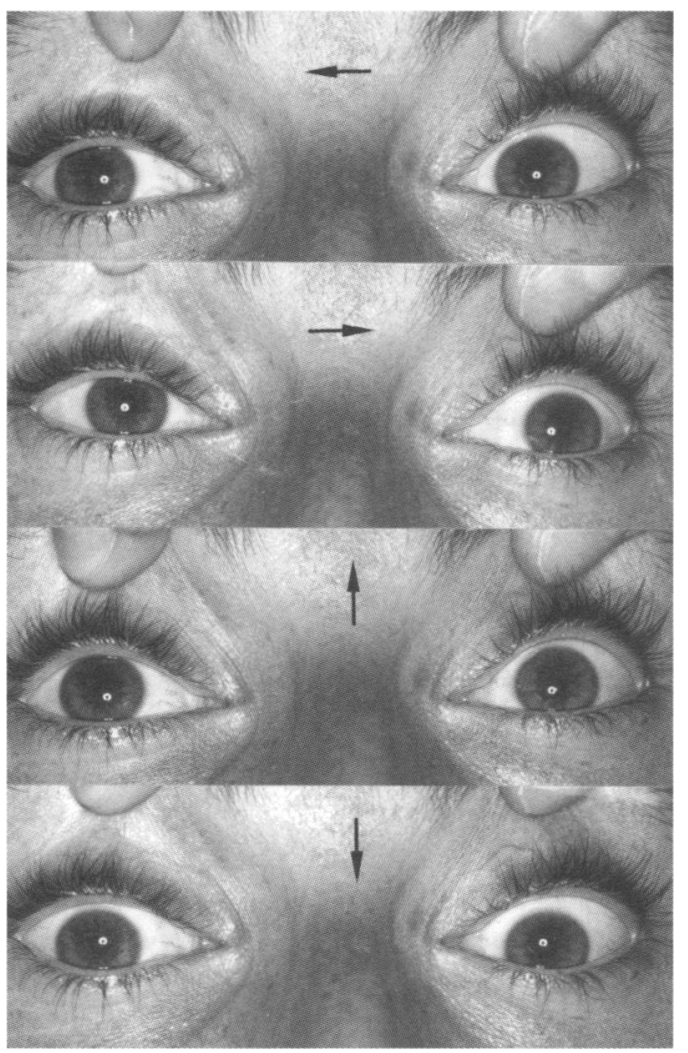

Figure 1 Photograph showing bilateral ptosis and ophthalmoplegia. phokinase: $192 \mathrm{U} / \mathrm{l})$. Four litres of normal saline and two vials of antivenom were administered intravenously during the first two hours. The patient's neurological picture improved steadily during the next two to three days, and two weeks after the snakebite neurological examination was normal.

Vipera aspis has been reported to be one of the most common snakes in the western part of southern Europe. Reactions to its venom include vomiting, diarrhoea, hypotension, shock, coagulopathy, thrombocytopenia, weakness, parasthesias, and bleeding. Neurotoxicity has been known to occur ${ }^{1-3}$ but is unusual and difficult to explain, especially as the venoms's main components of geographically focal populations of $V$ aspis may produce different neurotoxic activities. Recently, phospholipase A2 activities similar to vipoxin, which is known to be present in another European viper species ( $V$ ammodytes meridionalis), have been found in the venom of $V$ aspis. ${ }^{4}$ In the original clinical case reports of neurotoxic symptoms documented in human beings after $V$ aspis envenomation, the neurotoxicity was strictly localised in the cephalic muscles.

This case provides a clear description of neurotoxic envenoming involving muscles innervated by the third, fourth, and sixth cranial nerves in the absence of skeletal muscle damage. Extraocular muscle susceptibility in snake envenoming may be related to some basic properties of the neuromuscular junction anatomy and physiology, ${ }^{5}$ since other neuromuscular junctional disorders (such as myasthenia gravis and intermediate syndrome of organophosphorus insecticide) preferentially affect eye muscles.

1 Antonini G, Rasura M, Conti G, et al. Neuromuscular paralysis in Vipera aspis envenomation: pathogenetic mechanisms. F Neurol Neurosurg Psychiatry 1991;54:187.

2 De Haro L, Lang J, Bedry R, et al. Envenimations par viperes europennes. Etude multicentrique de tolerance du viperfav, nouvel antivenin par voie intraveineuse. Ann Fr Anerfav, nouvel antivenin par

3 Beer E, Putorti F. Dysphonia, an uncommon symptom of systemic neurotoxic envenomation by Vipera aspis bite. systemic neurotoxic envenomation by Vipera

4 Komori Y, Nikai T, Sugihara H. Comparison of the lethal components in Vipera aspis aspis and Vipera aspis zinnikeri components in Vipera aspis aspis and Vipera asp
venom. fournal of Natural Toxins 1998; 7:101-8.

5 Sanmuganathan PS, Senanayake N. Myasthenic syndrome Sanmuganathan PS, Senanayake N. Myasthenic syndrome
of snake envenoming: a clinical and neurophysiological study. Neurology 1991;41(suppl): 142. 